\title{
Synthesis and Photophysical Properties of the New Dyes Contained Benzenesulfonamide and 1,8-Naphthalimide
}

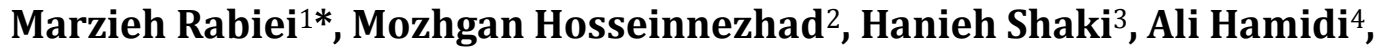
Soha Dehsorkhi ${ }^{1}$

${ }^{1}$ Advanced Materials Research Center, Materials Engineering Department, Najafabad Branch, Islamic Azad University, Najafabad 8514143131, Iran

${ }^{2}$ Department of Organic Colorants, Institute for Color Science and Technology, Tehran16656118481, Iran

${ }^{3}$ Department of Chemical Engineering, Faculty of Engineering, Golestan, Aliabad Katoul 1575949138, Iran

${ }^{4}$ Faculty of Technology, Linnaeus University, Vaxjo35195, Sweden

\begin{abstract}
In this study preparation and thermal, electrochemical, photophysical properties of the compounds are reported. New series of compounds consisting of 4-Allylamino-N-4-aminobenzenesulfonamide-1,8-naphthalimide, 4Amino-N-4-amino-N-(2-pyrimidinyl) benzenesulfonamide-1,8-naphthalimide and 4-Allylamino-N-4-amino- $\mathrm{N}-(2-$ pyrimidinyl) benzenesulfonamide-1,8-naphthalimide were synthesized via sonic method from intermediate 4-nitro-1,8naphthalimide by imidation, reduction and allylation reactions. These compounds were characterized by thin layer chromatography (TLC), differential scanning calorimetry (DSC), fourier transform infrared spectroscopy (FT-IR), ${ }^{1} \mathrm{H}-$ nuclear magnetic resonance (1HNMR), ${ }^{13} \mathrm{C}-\mathrm{NMR}$, liquid chromatography, UV-Vis spectroscopy and fluorimetry. New acceptor-donor compounds were obtained with the photoluminescence quantum yields (PLQY) of 33.68-79.70\% in solution and $0.85-3.39 \%$ in non-doped solid film. The synthesized dyes absorb electromagnetic radiation in the range of 434-440 nm and emit solid films exhibited fluorescence in the range of 561-614 $\mathrm{nm}$. The ionization potentials of the synthesized dyes were found to range from $6.00 \mathrm{eV}$ to $6.09 \mathrm{eV}$.
\end{abstract}

KEYWORDS: Ultrasound method, Naphthalimide dyes, Sulfonamides, Electrochemical properties, Photophysical properties

\section{INTRODUCTION}

Synthetic fluorescent labels are indispensable tools for quantitative detection in various fields of modern sciences [1].Conjugated compounds containing both donor and acceptor moieties have been extensively synthesized and studied because of their potential applications in electronics and optoelectronics [1, 2]. Several fluorescent dyes reported in the literature suffer from serious drawbacks such as their cumbersome synthesis, limited availability and biological interference [4].

Furthermore, many organic fluorescent dyes were prepared and their properties were investigated. One group of fluorescent dyes are 1,8-naphthalimide derivatives, which make a well-known class of dyes with a large range of applications $[1,2,3]$.

Derivatives of 1, 8-naphthalimide are widely used for various applications [1]. They were utilized in such fields as coloration and brightening of polymers [1], as laser active media [2,3], fluorescent markers in biology [4], anticancer agents [1], analgesics in medicine [2], fluorescence switchers and sensors [1,2], as electrontransporting and emitting materials in light emitting diodes [4,5]. They were also used in liquid crystal displays [1] and as ion probes [2,3]. Derivatives of 1,8naphthalimide generally have high electron affinity due to the existence of an electron-deficient center [4] and display good electron-transporting or hole-blocking capabilities.1,8-Naphthalimide moiety can be easily functionalized [4]. By introducing different electrondonating substituents at $\mathrm{C}-4$ position of 1,8-naphthalimide moiety the emission color of the compounds can be readily tuned from near infrared to pure blue $[2,3,4]$.

Substitution of electron donating groups usually raises the fluorescence emission, particularly when amino and allylamino groups are situated at the C-4 position [2,3]. Ultrasound is a kind of sound wave with the high frequency. When the ultrasound propagates in the medium, a series of physical and chemical changes occur in the media. The changes are accompanied with ultrasonic effect, mainly including the mechanical effect, acoustic cavitation effect, heating and chemical effects. Ultrasonic cavitation effect refers to the dynamic process of cavitation bubble with micro-gas-nuclear in the liquid [2].When the ultrasonic treatment is applied in solidliquid reaction, it can greatly enhance the rate of solidliquid heterogeneous reaction, realizes uniform mixing of reactants, accelerates the spread of reactants and products, promotes the formation of the new product phase and controls their particle size and distribution [29].Recently, ultrasound method has been employed for synthesis of organic components due to offering a versatile and facile pathway [2,3]. Based on our

*Corresponding Author: rabiei.marzieh@yahoo.com

Received: 15.02 .2019

Accepted: 20.02.2019

Published on: 27.02.2019

Marzieh Rabiei et al., 
knowledge there are no report on sonic synthesis of benzenesulfonamide substituent in 1,8-naphthalimde dyes.

\section{EXPERIMENTAL METHODS}

\subsection{Materials and Instrumentation}

4-Nitro-1, 8-naphthalicanhydride, 4 Amino benzenesulfonamide (sulfanilamide), 4-amino-N-(2pyrimidinyl) benzenesulfonamide (sulfadiazine) (SigmaAldrich),4-amino-N-2-hiazoylbenzenesulfonamide

(sulfathiazole) (Sigma Aldrich) and hydrochloric acid and zinc chloride (Merck Co.) were used without further purification. The FTIR spectra were recorded on a PerkinElmer Spectrum GX II FT-IROne spectrophotometer on a $\mathrm{KBr}$ disc. The ${ }^{1} \mathrm{H}-\mathrm{NMR}$ and ${ }^{13} \mathrm{C}$-NMR spectra (chemical shifts are given as $\delta$ in ppm) were recorded on a Bruker DRX AVANCE spectrometer operating at $500 \mathrm{MHz}$. The elemental analysis CHNS was determined on a Costech instruments (Elemental Combustion System 4010). Differential scanning calorimetry (DSC) measurements were carried out using a DSC (DSC 214 Polyma NETZ5CH) under nitrogen environment. Cyclic voltammetry measurements were performed on a PGSTAT 302, electrochemical experiments were carried out at room temperature using a three-electrode cell consisting of a platinum coil as counter electrode, a glassy carbon working electrode, and a silver wire as reference electrode. $0.1 \mathrm{M}$ solution of tetrabutylammonium hexafluorophosphate $\left(\mathrm{n}-\mathrm{Bu}_{4} \mathrm{NPF}_{6}\right)$ was used as supporting electrolyte at a scan rate of $100 \mathrm{mVs}^{1}$. For the measurements, silver reference electrode was calibrated against ferrocene/ferrocenium $\left(\mathrm{Fc} / \mathrm{Fc}^{+}\right)$redox couple as an internal standard [2].

Theoretical calculations and molecular simulations had been carried with Gaussian 09 and Gauss view software and carried out with B3LYP hybrid functional mixed with basis set of 6-311G. For evaluated compounds ground state geometries were optimized with no symmetry limitations to a local minimum, which was followed by frequency calculations also all simulations were conducted with polarizable continuum model using dichloromethane as solvent as implemented [2,3].

The UV-Vis absorption spectra were recorded on a Cecil 9200 double beam spectrophotometer and the fluorescence spectra were taken on a Perkin and Elmer LS50B spectrofluorimeter with both excitation and emission slits set at $10 \mathrm{~nm}$ and controlled by a personal computer data processing unit. To record photoluminescence decay curves dependencies on laser flux, with Pico Quant LDH-D-C-375 laser with wavelength equals $374 \mathrm{~nm}$ as the excitation source were used and the ionization potential (IP) of the vacuum deposited films was obtained using photoelectron emission spectrometry in air $[2,3]$.

\section{SYNTHESIS OF INTERMEDIATES AND DYES 3.1 General Procedure for the Preparation of Intermediate}

A mixture of $0.02 \mathrm{~mol}$ 4-nitro-1,8-naphthalimide (1) and $0.02 \mathrm{~mol}$ amine in $10 \mathrm{ml}$ water was sonicated at 35
$\mathrm{KHz}$ in a sonic bath maintained at $25^{\circ} \mathrm{C}$. Thin-layer chromatography (TLC) was performed at the end of the reaction, and then the contents were filtered and the synthesis route is presented in Scheme 1.

\section{4-Nitro-N-4-aminobenzenesulfonamide-1,8- naphthalimide (2)}

$\mathrm{Y}=78 \%$; $\mathrm{MP}=315.5^{\circ} \mathrm{C}$; FT-IR $(\mathrm{KBr})\left(\mathrm{cm}^{-1}\right): 3355: \mathrm{NH}$ str., 1711, 1658: C=0 str., 1521, 1325: $\mathrm{NO}_{2}$ str., 1236: $\mathrm{SO}_{2}$ str.; ${ }^{1} \mathrm{HNMR}(500 \mathrm{MHz}, \mathrm{CDC} 13, \delta / \mathrm{ppm}): 7.60$ (s, 2H, NH2), 7.65$7.68(\mathrm{~d}, 2 \mathrm{H}, J=7.5 \mathrm{~Hz}), 7.82-7.86(\mathrm{~d}, 2 \mathrm{H}, J=7.1 \mathrm{~Hz}), 7.92(\mathrm{t}$, $1 \mathrm{H}), 8.21-8.26$ (d, 4H, J=7.8 Hz); Elem. Anal. Calcd. (\%) for $\mathrm{C}_{18} \mathrm{H}_{11} \mathrm{~N}_{3} \mathrm{O}_{6} \mathrm{~S}$ : C, 54.40; N, 10.57; H, 2.77. Found: C, 54.49; N, 10.39; H, 2.82.

\section{4-Nitro-N-4-amino-N-(2-pyrimidinyl) \\ benzensulfonamide-1,8-naphthalimide (3)}

$\mathrm{Y}=71 \%$; $\mathrm{MP}=319^{\circ} \mathrm{C}$; FT-IR $(\mathrm{KBr})\left(\mathrm{cm}^{-1}\right):$ 3256: NH str., 1708, 1650: C=0 str., 1517, 1339: $\mathrm{NO}_{2}$ str., 1241: $\mathrm{SO}_{2}$ str.; ${ }^{1} \mathrm{HNMR}\left(500 \mathrm{MHz}, \mathrm{CDC}_{3}, \delta / \mathrm{ppm}\right): 6.98-7.03(\mathrm{t}, 1 \mathrm{H}), 7.55-$ 7.62 (d, $2 \mathrm{H}, J=7.3 \mathrm{~Hz}$ ), 7.78-7.84 (d, $3 \mathrm{H}, J=7.5 \mathrm{~Hz}), 8.11-8.19$ (d, 2H),8.34-8.39 (d, 4H, J=7.7 Hz), 11.22 (s, 1H, NH); Elem. Anal. Calcd. (\%) for $\mathrm{C}_{22} \mathrm{H}_{13} \mathrm{~N}_{5} \mathrm{O}_{6} \mathrm{~S}$ : C, 55.57; N, 14.73; $\mathrm{H}$, 2.73. Found: $\mathrm{C}, 54.89 ; \mathrm{N}, 14.11 ; \mathrm{H}, 2.19$.

\section{4-Nitro-N-4-amino-N-2-thiazoyl \\ benzenesulfonamide-1,8-naphthalimide (4)}

$\mathrm{Y}=74 \%$; $\mathrm{MP}=281{ }^{\circ} \mathrm{C}$; FTIR $(\mathrm{KBr})\left(\mathrm{Cm}^{-1}\right): 3225: \mathrm{NH}$ str., 1700, 1658: $\mathrm{C}=0$ str., 1521, 1345: $\mathrm{NO}_{2}$ str., 1239: $\mathrm{SO}_{2}$ str.; 1HNMR (500MHz, CDC13, $\delta / \mathrm{ppm}): 6.78-6.81(\mathrm{~d}, 1 \mathrm{H}, J=4.8$ $\mathrm{Hz})$, 7.21-7.28 (d, $1 \mathrm{H}, J=6.5 \mathrm{~Hz}), 7.42-7.49$ (d, $2 \mathrm{H}, J=7.2 \mathrm{~Hz})$, 7.63-7.72 (d, 2H, J=7.1 Hz), 7.98-8.05 (d, 2H),8.12 (t, 1H), 8.44-8.49 (d, 4H, J=7.5 Hz), 11.34 (s, 1H, NH); Elem. Anal. Calcd. (\%) for $\mathrm{C}_{21} \mathrm{H}_{12} \mathrm{~N}_{4} \mathrm{O}_{6} \mathrm{~S}_{2}$ : C, 52.5; N, 11.66; H, 2.50 . Found: C, 53.17; N, 12.28; H, 2.34.

\subsection{General Procedure for the Preparation of Organic Dyes}

A mixture of 0.03 mol intermediate $(2,3$ or 4$)$ and was dissolved in $8 \mathrm{~mL}$ of acetic acid and $0.015 \mathrm{~mol}$ of $\mathrm{Fe}$ powder was added in the mixture. The reaction solution was sonicated at $35 \mathrm{KHz}$ in a sonic bath maintained at 25 ${ }^{\circ} \mathrm{C}$ for $30 \mathrm{~min}$. Thin-layer chromatography (TLC) was performed at the end of the reaction, and then the contents were filtered.

\section{4-Allylamino- $N$-4-aminobenzenesulfonamide-1, 8- naphthalimide (Dye 1)}

$\mathrm{Y}=82 \%$; $\mathrm{MP}=229.6^{\circ} \mathrm{C}$; FT-IR $(\mathrm{KBr})\left(\mathrm{cm}^{-1}\right): 3368$ : $\mathrm{NH}$ str., 1695, 1642: C=0 str., 1244, 1159: $\mathrm{SO}_{2}$ str.; ${ }^{1} \mathrm{HNMR}$ (500MHz, $\mathrm{CDC1}_{3}, \delta / \mathrm{ppm}$ ): 3.23 (s, $1 \mathrm{H}, \mathrm{NH}$ allyl), 4.19 (s, $2 \mathrm{H}$, allyl $\left.\mathrm{NCH}_{2}\right), 4.85\left(1 \mathrm{H},=\mathrm{CH}_{2}\right.$ allyl), $5.28(\mathrm{~s}, 1 \mathrm{H}, \mathrm{CH}=$ allyl), 6.82-6.89 (d, $1 \mathrm{H}, J=7.6 \mathrm{~Hz}), 7.17-7.25(\mathrm{~d}, 2 \mathrm{H}$, $J=7.5 \mathrm{~Hz}), 7.52\left(\mathrm{~s}, 2 \mathrm{H}, \mathrm{NH}_{2}\right), 7.68(\mathrm{t}, 1 \mathrm{H}), 7.74-7.59(\mathrm{~d}, 3 \mathrm{H}$, $J=7.1 \mathrm{~Hz}$ ), 8.17-8.23 (d, 3H, J=7.7 Hz); Elem. Anal. Calcd. (\%) for $\mathrm{C}_{21} \mathrm{H}_{17} \mathrm{~N}_{3} \mathrm{O}_{4} \mathrm{~S}$ : C, 61.91; N, 10.32; H, 4.17. Found: C, 62.15; N, 10.69; H, 4.95.

Marzieh Rabiei et al., 
4-Amino-N-4-amino-N-(2-pyrimidinyl)

benzenesulfonamide-1,8-naphthalimide (Dye 2)

$\mathrm{Y}=71 \%$; $\mathrm{MP}=259.5^{\circ} \mathrm{C}$; FTIR $(\mathrm{KBr})\left(\mathrm{Cm}^{-1}\right): 3389$ : NH str., 1690, 1640: $\mathrm{C}=0$ str., 1239, 1144: $\mathrm{SO}_{2}$ str.; ${ }^{1} \mathrm{HNMR}$ (500MHz, CDC1 3 , $\delta / \mathrm{ppm}): 6.78-6.86(\mathrm{~d}, 1 \mathrm{H}, J=7.2 \mathrm{~Hz}), 7.12$ $(\mathrm{t}, 1 \mathrm{H}), 7.26-7.34(\mathrm{~d}, 2 \mathrm{H}, J=7.3 \mathrm{~Hz}), 7.41\left(\mathrm{~s}, 2 \mathrm{H}, \mathrm{NH}_{2}\right), 7.54-$ 7.58 (d, 3H, J=7.5 Hz), $7.82(\mathrm{t}, 1 \mathrm{H}), 7.89-7.93$ (d, 3H, J=7.6 $\mathrm{Hz})$, 8.07-8.16 (d,1H, J=7.7 Hz), 10.98 (s, 1H, NH); Elem. Anal. Calcd. (\%) for $\mathrm{C}_{22} \mathrm{H}_{15} \mathrm{~N}_{5} \mathrm{O}_{4} \mathrm{~S}$ : C, 59.32; N, 15.73; $\mathrm{H}$, 3.37. Found: C, 58.63; N, 14.70; H, 3.72 .

\section{4-Allylamino-N-4-amino-N-(2-pyrimidinyl) benzenesulfonamide-1,8-naphthalimide (Dye 3)}

$\mathrm{Y}=75 \%$; $\mathrm{MP}=267.8^{\circ} \mathrm{C}$; FTIR $(\mathrm{KBr})\left(\mathrm{Cm}^{-1}\right): 3379: \mathrm{NH}$ str., 1695, 1653: C=0 str., 1236, 1158: $\mathrm{SO}_{2}$ str.; ${ }^{1} \mathrm{HNMR}$ (500MHz, CDC1 3 , $\delta / \mathrm{ppm}): 6.82-6.88(\mathrm{~d}, 1 \mathrm{H}), 6.92-6.97(\mathrm{~d}$, $1 \mathrm{H}), 7.16-7.21$ (d, $1 \mathrm{H}, J=7.3 \mathrm{~Hz}$ ), 7.32-7.38 (d, $2 \mathrm{H}, J=7.3 \mathrm{~Hz}$ ), $7.56\left(\mathrm{~s}, 2 \mathrm{H}, \mathrm{NH}_{2}\right), 7.62-7.69$ (d, 2H, J=7.3 Hz), $7.95(\mathrm{t}, 1 \mathrm{H})$, 7.91-7.98 (d, 3H, J=7.5 Hz), $11.17(\mathrm{~s}, 1 \mathrm{H}, \mathrm{NH})$; Elem. Anal. Calcd. (\%) for $\mathrm{C}_{21} \mathrm{H}_{14} \mathrm{~N}_{4} \mathrm{O}_{4} \mathrm{~S}_{2}$ : C, 56.0; N, 12.44; H, 3.11 . Found: C, 56.68; N, 12.86; H, 3.61.

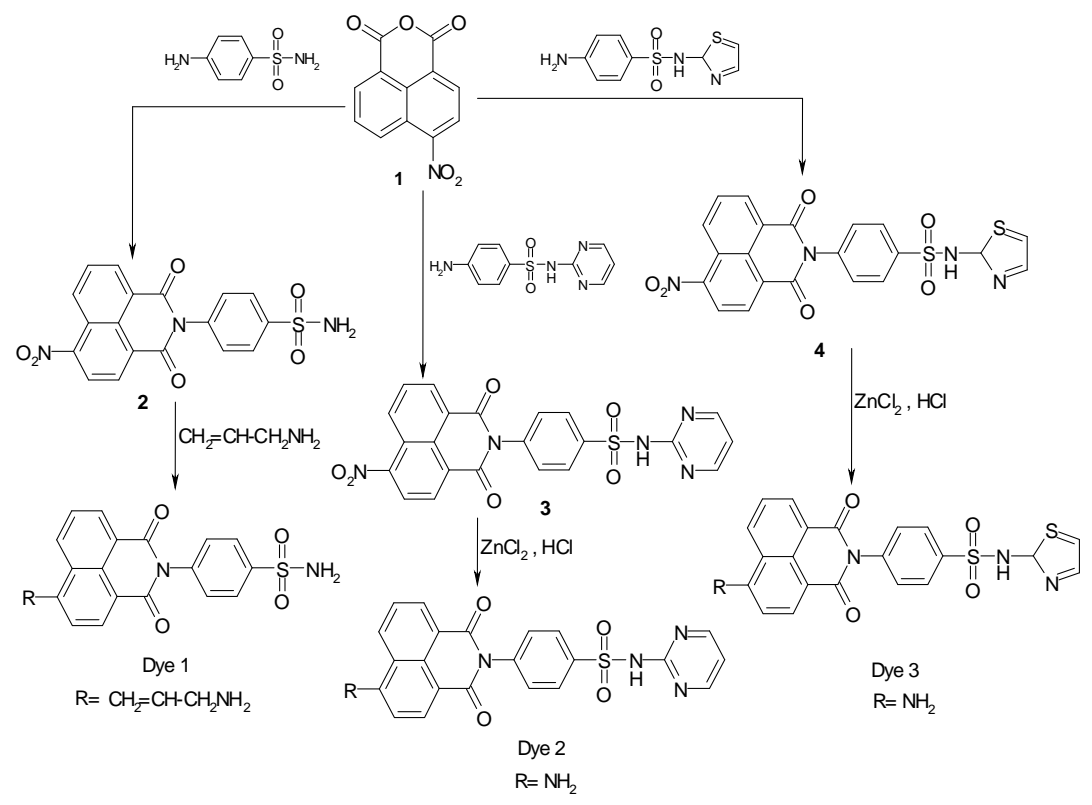

Scheme 1 Synthesis route of Dyes 1-3

\section{RESULTS AND DISCUSSION}

\subsection{Geometries and frontier orbitals}

The molecular configuration and the frontier molecular orbital distribution of Dye 1-3 were analyzed by density functional theory (DFT) calculations using Gaussian 09 software at the B3LYP/6-311G (d,p) level. The theoretical geometries and the distribution of HOMO and LUMO of synthesized dyes are presented in Figure 1.

\subsection{UV and Fluorescence properties}

Absorption and photoluminescence (PL) spectra of the dilute solutions of compounds $\left(10^{-5} \mathrm{M}\right)$ and solid films are shown in Figure 2 and 3 respectively and wavelength ranges of the main absorption bands and fluorescence were shown in Table 1.

According to the Figure 2, the region of strong absorption bands $(\sim 413-440 \mathrm{~nm})$ can be attributed to the localized aromatic $\pi-\pi^{*}$ transitions of donor units in compounds. The shift to longer wavelengths observed for compounds especially for dye 2 , which is suggested an increase in the conjugation level of the $\pi$ orbitals [2]. The effect of different solvents on the emission spectra of compounds were studied and bathochromic shift of PL maxima of solutions increases with increasing dielectric constant of solvents in the order Isopropanol $(\varepsilon=17.9)$, Methanol $(\varepsilon=32.7)$ and Acetonitrile $(\varepsilon=37.5)$, with an overall different relocation. The wavelengths of maximum intensities exhibited bathochromic shifts leads to strong red shift from the lowest polarity (Isopropanol) to highest polarity (Acetonitrile) ambient, compared to the individual $\mathrm{D}$ and $\mathrm{A}$ emission spectra and PL spectra move to longer wavelengths with increasing polarity of solvent, showing a strong positive solvatochromism and as displayed previously in other D-Atype of molecules [2,3]. Furthermore, increases of solvents polarity observed CT energy red shifted and investigated in less LES (Local Excited State) parameter and higher energy difference between $\mathrm{CT}_{\text {axial }}$ and $\mathrm{CT}_{\text {equatorial }}[2,3,4]$ and indicates that existed certain degree of CT character with a large dipole moment which is derived from low lying singlet excited state [2,3].Moreover solvent sensitivity to polarity can be analyzed in terms of difference dipole moments in the ground and excited states $[2,3]$.The spectra of synthesized dyes in solid film state (Figure 3) shows orange color for dye 1 , green color for dye 2 and dye 3 near to yellow color respectively and they are characterized by chromaticity coordinates and criteria of CIE coordinates and submitted in Figure S6.

Marzieh Rabiei et al., 


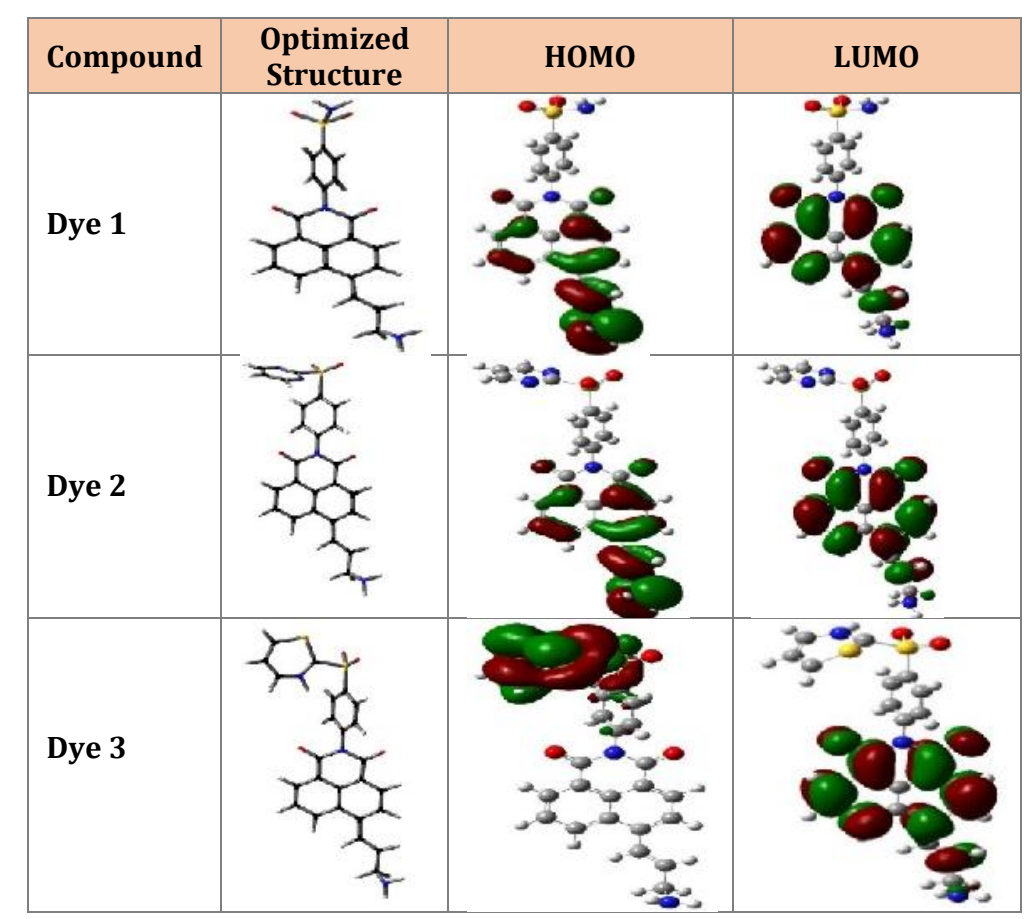

Figure 1 HOMO and LUMO of dyes 1-3 calculated at B3LYP/6-311G (d,p) level

The value of PLQY for dye 1 was $79.70 \%$ in acetonitrile and versus of solid film was failed with value $0.85 \%$ and PLQY of dye 2 and 3 also in Acetonitrile and solid film were 66.94 and $1.78 \%$ (for dye 2) and $33.68 \%$ and $3.39 \%$ (for dye 3) respectively.Low value of PLQY of the solid film of dyes can apparently be explained by large dipole moment of the compounds. However, many luminophores are highly luminescent in dilute solutions and light emissions are often quenched in the solid state due to aggregation of their chromophoric units in the condensed phase [2]. ACQ affect the solutions and dispersions of dyes $1-3$, in water/THF mixtures at room temperature, were studied in Figures 4 and Figures S2.

The $\pi-\pi$ supramolecular interactions also play an important role in the ACQ. This data (Figure 4-b) shows that the properly disturbing the close molecular packing and diminishing the intermolecular quenching effects are advantageous for increasing the PLQY value of solutions phases.

In contrast, although $\pi-\pi$ interactions, it shows loose packing with weak molecular interactions, thus resulting in non-radiative of pathways through rotation or vibration [2]. Fluorescence decay profiles of solutions and solid films were recorded using single photon counting spectrofluorimeter. PL decays were monitored at the corresponding emission maximum of the dyes and software experimental fluorescence allowed the fitting of value the decay spectra 1 until 1.3 and considered excitation of instrument response $374 \mathrm{~nm}$. According to the Figure 5 and Table S1, appearing of the slower decay dyes for dye 2 in solid film, occurred 4.64 ns that probably reasons are associated with the weak intermolecular interactions or crystalline aggregate formations in the neat films [3]. Moreover, the spectra of life time for dyes in solutions presented in Figure S3.

Table 1 Spectroscopic properties and PLQY of the dyes specified in mode of non-polar and polar solutions and solid film

\begin{tabular}{|l|l|l|l|l|l|l|l|l|l|l|}
\hline & \multicolumn{2}{|c|}{ Isopropanol } & \multicolumn{3}{c|}{ Methanol } & \multicolumn{3}{c|}{ Acetonitrile } & \multicolumn{3}{c|}{ Solid Film } \\
\cline { 2 - 11 } Dye & $\begin{array}{c}\lambda_{a b s}^{\max } \\
\mathbf{n m}\end{array}$ & $\begin{array}{c}\lambda_{F}^{\max } \\
\mathbf{n m}\end{array}$ & $\begin{array}{c}\lambda_{a b s}^{\max }, \\
\mathbf{n m}\end{array}$ & $\begin{array}{c}\lambda_{F}^{\max } \\
\mathbf{n m}\end{array}$ & $\begin{array}{c}\lambda_{a b s}^{\max } \\
\mathbf{n m}\end{array}$ & $\begin{array}{c}\lambda_{F}^{\max } \\
\mathbf{n m}\end{array}$ & $\begin{array}{c}\text { PLQY } \\
\mathbf{\%}\end{array}$ & $\begin{array}{c}\lambda_{a b s}^{\max } \\
\mathbf{n m}\end{array}$ & $\begin{array}{c}\lambda_{F}^{\max }, \\
\mathbf{n m}\end{array}$ & $\mathbf{P L Q Y \%}$ \\
\hline $\mathbf{1}$ & 428 & 503 & 436 & 520 & 426 & 525 & 79.70 & 434 & 614 & 0.85 \\
\hline $\mathbf{2}$ & 429 & 507 & 413 & 522 & 423 & 528 & 66.94 & 440 & 561 & 1.78 \\
\hline $\mathbf{3}$ & 425 & 505 & 422 & 525 & 424 & 527 & 33.68 & 438 & 586 & 3.39 \\
\hline
\end{tabular}

\section{Marzieh Rabiei et al.,}




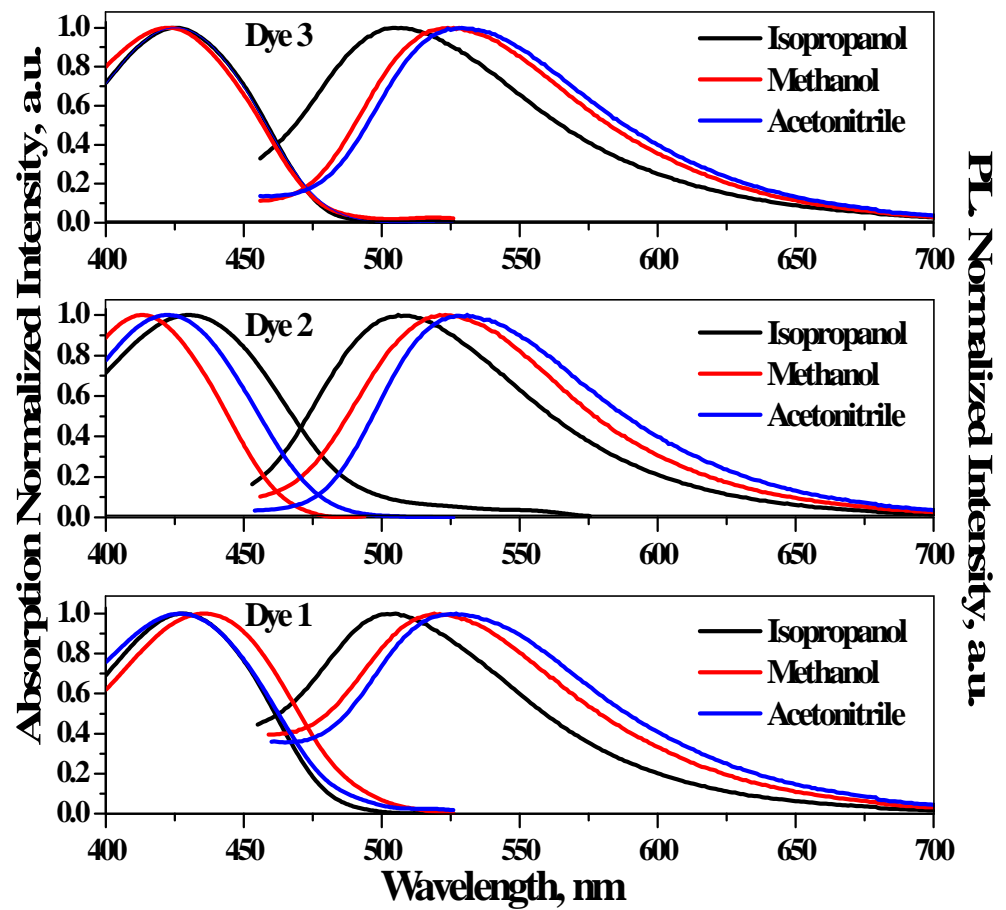

Figure 2 Absorption spectra and photoluminescence (PL) spectra of dilute solutions in different solvents (10-5 $\mathrm{M}$ ) of dyes 1-3 (Excitation=330nm)

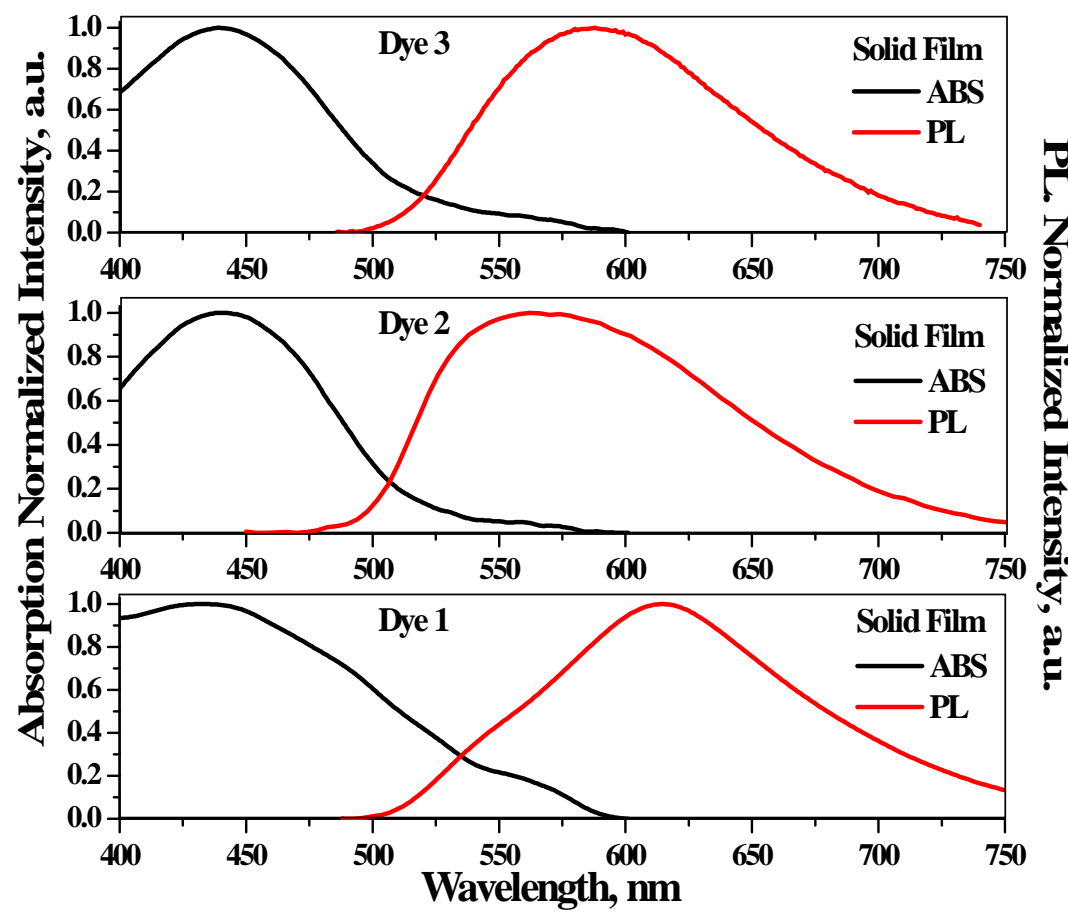

Figure 3 Absorption spectra and photoluminescence (PL) spectra of solid film of dyes 1-3 (Excitation=330nm)

Marzieh Rabiei et al., 

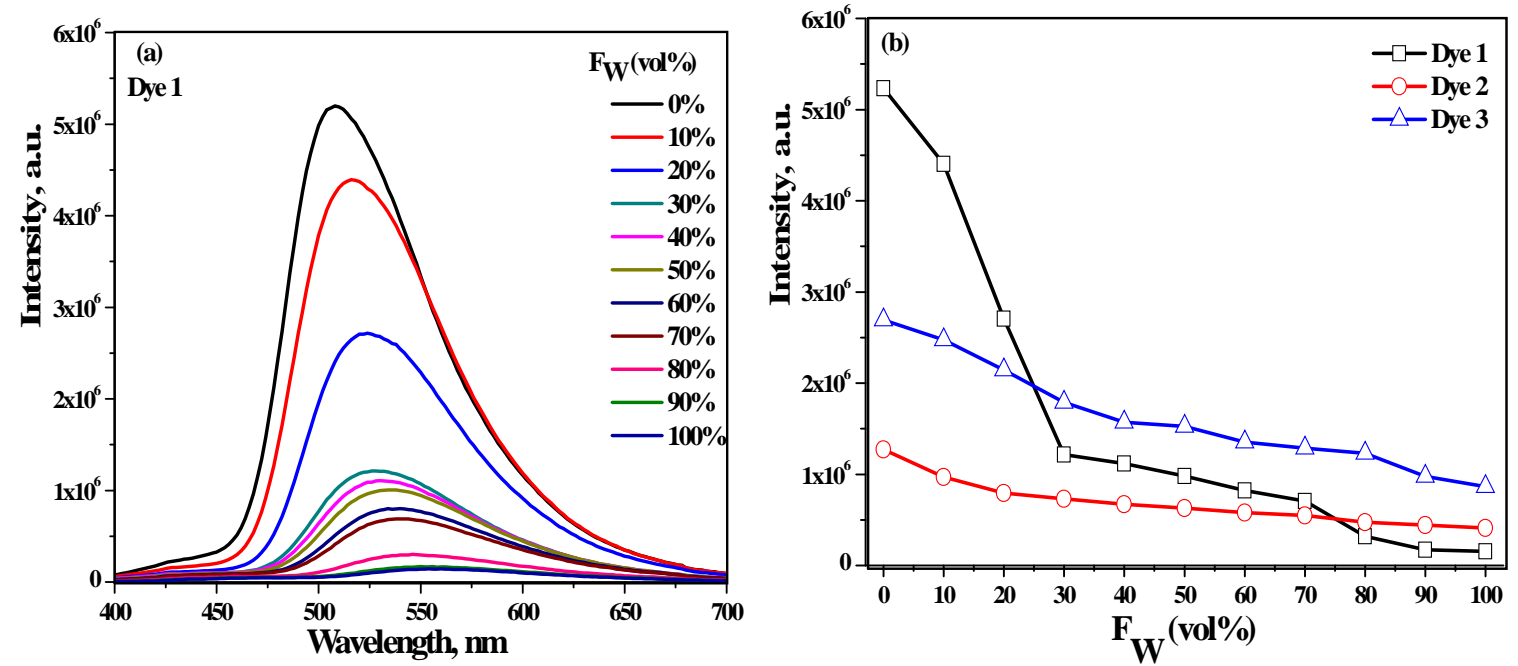

Figure 4 (a) PL spectra of Dye 1 in the THF/Water mixtures and (b) The inset plot of Dyes indicated the relationship between PL maximum intensities and water volume fraction in THF/Water mixtures

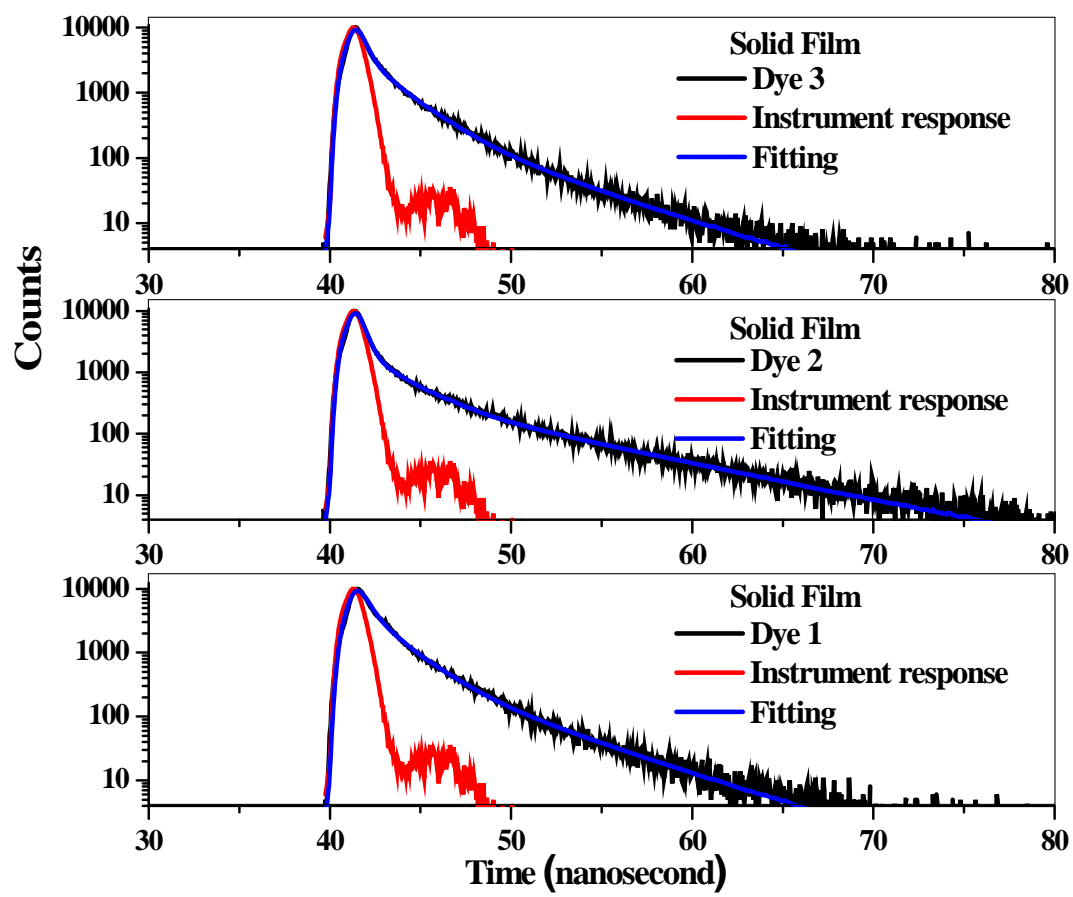

Figure 5 PL decay of Dyes equilibrated solid film at room temperature

\subsection{Electrochemical and Photoelectrical Properties}

The electrochemical characteristics of dyes are summarized in Table 2. As well as Cyclic Voltammetry (CV) of dyes are shown in Figure S1. The ionization potential $\left(\mathrm{IP}_{\mathrm{PV}}^{\mathrm{CV}}\right)$ values of dyes were estimated from the onset potentials of the first oxidation event after calibration of the measurements against ferrocene. $\mathrm{I}_{\mathrm{P}}^{\mathrm{CV}}$ for compounds were found to be range of 5.67-5.70V.

Furthermore, Ionization potentials $\left(\mathrm{I}_{\mathrm{P}}^{\mathrm{PE}}\right)$ for vacuum deposited layers of compounds were taken from photoelectron emission spectra and presented in Figure 6. Electron affinities $\left(\mathrm{E}_{\mathrm{A}}^{\mathrm{CV}}\right)$ of dyes1, 2 and 3were estimated to be $3.12,3,13$ and $3.19 \mathrm{eV}$, respectively.

Marzieh Rabiei et al., 
Table 2. Investigation of Electrochemical properties and HOMO/LUMO energies of dyes 1-3

\begin{tabular}{|c|c|c|c|c|c|c|c|c|}
\hline Compound & $\begin{array}{c}\text { Eox } \\
(\mathbf{V})\end{array}$ & $\begin{array}{c}\text { Ered } \\
(\mathbf{V})\end{array}$ & $\begin{array}{c}\text { EAcv } \\
\mathbf{( e V )}\end{array}$ & $\begin{array}{c}\text { IPcV } \\
\mathbf{( e V )}\end{array}$ & $\begin{array}{c}\text { LUMO } \\
\mathbf{( e V}\end{array}$ & $\begin{array}{c}\text { HOMO } \\
(\mathbf{e V})\end{array}$ & $\begin{array}{c}\text { Egopt } \\
(\mathbf{e V})\end{array}$ & $\begin{array}{c}\text { IPPE } \\
(\mathbf{e V})\end{array}$ \\
\hline $\mathbf{1}$ & 0.79 & -1.19 & 3.12 & 5.70 & 3.09 & 5.43 & 2.58 & 6.00 \\
\hline $\mathbf{2}$ & 0.77 & -1.21 & 3.13 & 5.68 & 3.05 & 6.55 & 2.55 & 6.09 \\
\hline $\mathbf{3}$ & 0.76 & -1.20 & 3.19 & 5.67 & 2.98 & 6.50 & 2.48 & 6.03 \\
\hline
\end{tabular}

\section{Explanations about parameters of Table:}

Eox: Potential of onset of oxidation and estimated from CV

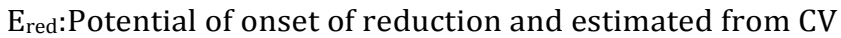

EAcv: Calculated with the relation $\mathrm{EA}_{\mathrm{CV}}=-\left(|\mathrm{IP} \mathrm{CV}|-\mathrm{E}_{\mathrm{g}} \mathrm{opt}\right)$

$\mathrm{IP}_{\mathrm{CV}}=$ Ionization potentials calculated with the relation $\left|-\left(1.4 \times 1 \mathrm{e} \times \mathrm{E}_{\mathrm{ox}} \mathrm{Vs} \mathrm{Fc} / \mathrm{V}\right)-4.6\right| \mathrm{eV}$

LUMO: Energy level Estimated by DFT, HOMO: Energy level Estimated by DFT

Egopt: Calculated with the relation $1239.75 / \lambda_{\text {of UV spectra (diluted Acetonitrile) }}$

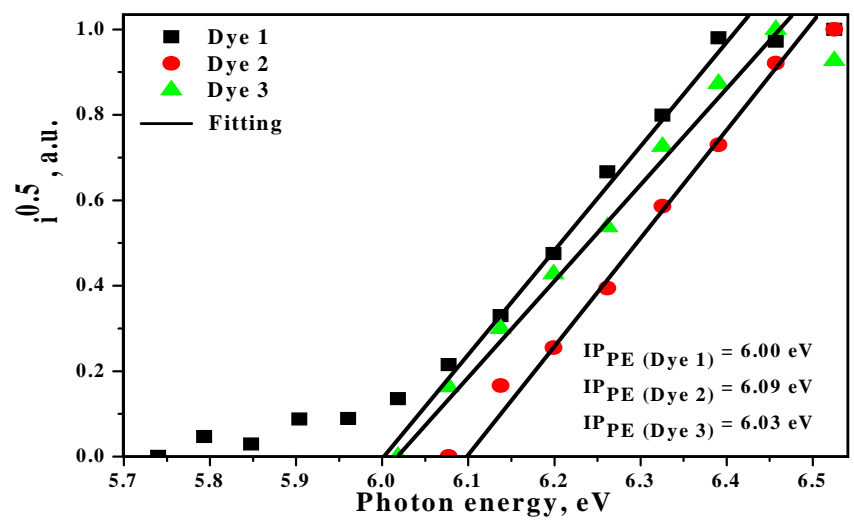

Figure 6 Photoelectron emission spectra of compounds

\section{CONCLUSIONS}

In this study, a series of novel 1,8-naphthalimde dyes incorporated with benzenesulfonamide heterocycles with ultrasound method was prepared. The synthesized dyes and their intermediates were characterized. According to the photophysical properties of prepared dyes the absorption spectra were in the range of 434-440 $\mathrm{nm}$ in solid film, while photoluminescence spectra were in the range of 561-614 nm. Furthermore, the result of ionization potential of dyes demonstrated values between 6-6.09 eV. The PLQY of dyes in acetonitrile were high values and aggregation caused quenching (ACQ) for dyes reported. Moreover the $\tau$ of PL Decay spectra of dye 3 was higher than dye 1 and 2 in solid film (7.07 (19.83\%)). Based on our knowledge there are no report on sonic synthesis of benzenesulfonamide substituent in 1,8naphthalimde dyes.

\section{ACKNOWLEDGMENT}

The authors sincerely thank the Iran National Science Foundation: INSF for making this investigation possible.

\section{REFERENCES}

[1]. Lei, ZH., Wang,J., Tian, Y., Song,G., Zhao,G., Xu, H., 2015. Synthesis and application of clickable and biocompatible fluorescent glycosyl labels,"Dyes and Pigments. 113, 627-633.
[2]. Gudeika, D. Grazulevicius JV., Butkute,R., Juska,G., Gruodis,A., Jursenas,S., 2015. Structure-properties relationship of the derivateives of carbazole and 1,8naphthalimide: Effects of the substitution and the linking topology, Dyes and Pigments. 114, 239-252.

[3]. Pron, A., Reghu, RR., Rybakiewicz, R., Cybulski, H., Djurado, D., Grazulevicius, JV., Triarylamine substituted arylene bisimides as solution processable organic semiconductors for field effect transistors. Effect of substituent position on their spectroscopic, electrochemical, structural, and electrical transport properties, Phys Chem C. 115, 15008-15017.

[4]. Yang,J., Li,J., Hao,P., Qui,F., Liu,M., Zhang,Qi., Shi,D., 2015. Synthesis, optical properties of multi donoracceptor substituted AIE pyridine derivatives dyes and application for Au3+ detection in aqueous solution,"Dyes and Pigments. 116, 97-105.

[5]. Rezanejade Bardajee,G., Li,AY., Haley,JC., Winnik,MA., The synthesis and spectroscopic properties of novel, functional fluorescent naphthalimide dyes, Dyes and Pigments. 79, 24-32.

[6]. Grabchev, I. Betcheva, R. 2001. Copolymerization and photostabilization of methylmethacrylate with 1,8naphthalimide fluorescent brighteners, J Photochem Photobiol. A. Chem. 142, 73-78. 
[7]. Bojinov, NI. Georgiev, PS. Nikolov, "Synthesis and photophysical properties of fluorescence sensing ester- and amidoamine-functionalized 1,8naphthalimides,"J. Photochem. Photobiol. A. Chem. 193, 129-138 (2008).

[8]. Gregory,P., High technology applications of organic colorants Plenum,"New York 5-15.

[9]. Hrdlovic,P., Chmela,S., Danko, M., Sarakha, M., Guyot,G., 2008. Spectral properties of probescontaining benzothioxanthene chromophore linked with hindered amine in solution and in polymer matrices," J Fluoresc. 18, 393-402.

[10]. Samanta, A., Ramachandram,B., Saroja,G., 1996. An investigation of the triplet state properties of 1,8-naphthalimide: a laser flash photolysis study, Photochemistry and Photobiology A: Chemistry. 101, 29-32.

[11]. Ye,G., Zhao,T., Jin,Z., Gu, P., Mao,J., Xu,Q., 2012. The synthesis and NLO properties of 1,8naphthalimide derivatives for both femtosecond and nanosecond laser pulses, Dyes Pigm. 94, 271-277.

[12]. Yin,H., Zhu,W., Xu,Y., Dai, M., Qian,X., Li, Y., 2011. Novelaliphatic $\mathrm{N}$-oxide of naphtal- imides as fluorescent markers for hypoxic cells in solid tumor, Eur J Med Chem. 46, 3030-3037.

[13]. Lai,C.M., Garner ,D.M., Gray, J.E., Brogdon, B.L., Peterman,V.C., $\quad$ Pieniaszek, H.J., 1998. Determination of bisnafide, a novel bisnaphthalimide anticancer agent, in human plasma by high-performance liquidchromatography with UV detection, Pharm Biomed. 17, 427-434.

[14]. Zhang,Y., Zhou,C. 2011. Synthesis and activities of naphthalimide azoles as a new type ofantibacterial and antifungal agents, Bioorg Med Chem Lett. 21, 4349-4352.

[15]. Pina-Luis, G., Martínez-Quiroz, M., Ochoa Terán, A., Santacruz, H., Ortega, E. Mendez-Valenzuela, 2013. New dual emission fluorescent sensor for $\mathrm{pH}$ and $\mathrm{Pb}$ (II) based on bis (napfthalimide) derivative, J Lumin. 134, 729-738.

[16]. Lv,H., Liu,J., Zhao,J., Zhao,B., Miao,J., 2013. Highly selective and sensitive $\mathrm{pH}$-responsive fluorescent probe in living hela and HUVEC cells," Sens Actuat B Chem.177, 956-963.

[17]. Zhou,J., Chen, P., Wang,X., Wang,Y., Wang,Y., Li, F., 2014. Charge-transfer-featured materialspromising hosts for fabrication of efficient OLEDs through triplet harvesting via triplet fusion, Chem Commun. 50, 7586-7589.

[18]. Yin,S., Liu,X., Li,C., Huang,W., Li,W., He,B., 1998. Electroluminescent properties of naphthalimide derivative thin film devices, Thin Solid Films. 325, 268-270.

[19]. Grabchev, I., $\quad$ Moneva,I., $\quad$ Bojinov,V., Guittonneau,S., 2000. Synthesis and properties of fluorescent 1,8-naphthalimide dyes for application in liquid crystal displays, J Mater Chem. 10, 1291-1296.

[20]. Kumar, A., Vanita,V., Walia,A., Kumar,S.N., 2013. $\mathrm{N}, \mathrm{N}$-dimethylamino ethylaminoanthrone-A chromofluorogenic chemosensor for estimation of $\mathrm{Cu} 2+$ aqueous medium and HeLa cells imaging, Sens Actuat B Chem.177, 904-912.

[21]. Prapawattanapol, VS. N. Lee, K. Grudpan, A. Pet som, 2013.Hg2+- Induced self-assembly of a naphthalimide derivative by selective 'turnon'monomer/ excimer emissions, J Lumin. 134.

[22]. Cacialli,F, Friend, RH., Bouche, LP. Barny, H. Fac oetti, F. Soyer, etal,"Naphthalimide side-chain polymers for organic light-emitting diodes: band-offset engineering and role of polymer thickness,"J Appl Phys. 83, 2343-2356 (1998).

[23]. Takahashi,S., Nozaki,K., Kozaki,M. Suzuki, K. S., Keyaki,A., Ichimura, Photoinduced electron transfer of $\mathrm{N}-[(3-$ and 4-diarylamino)phenyl]1,8-naphthalimide dyads: orbital-orthogonal approach in a short-linked d-a system, J Phys Chem A. 112, 2533-2542.

[24]. Islam, C.C., Cheng, A., Chi,S.H., Lee,S.J., Hela,G.P. Chen,C., 2005. Aminonaphthalic anhydrides as red-emitting materials: electroluminescence, crystal structure, and photophysical properties, Phys Chem B. 109, 5509-5517.

[25]. Yang,J.X., Wang,X.L., Wang,X.M., XuThe, L.H. 2005. Synthesis and spectral properties of novel 4-phenylacetylene-1,8-naphthalimide derivatives, Dyes Pigm. 66, 83-87.

[26]. Magalhaes,J.L.,Pereira, R.V., Triboni, E.R., Filho Berci, P., Gehlen, M.H., Nart, F.C., 2006. Solvent effect on the photo physical properties of 4phenoxy- $N$-methyl-1,8-naphthalimide, J Photochem Photobiol A. 183, 165-170.

[27]. Bojinov,VB., Panova,IP., 2008. Photo-stability of yellow-green emitting 1,8-naphthalimides containing built-in s-triazine UV absorber and HALS fragments and their acrylonitrile copolymers, Polym. Degrad. Stabil. 93, 11421150.

[28]. Bojinov,VB., Konstantinova,TN., 2007. Fluorescent 4-(2,2,6,6-tetramethylpiperidin-4-

ylamino)-1,8-naphthalimide $\mathrm{pH}$ chemosensor based on photoinduced electron transfer, Sensor Actuat. B - Chem. 123, 869-876.

[29]. Guorong $\mathrm{Hu}$, Xiaoming Xie, Yanbing Cao, Lian $\mathrm{Xu}$, $\mathrm{KeDu}$, Weigang Wang, Zhongdong Peng, 2019. Ultrasonic-assisted synthesis of $\mathrm{LiFePO} 4 / \mathrm{C}$ composite for lithium-ionbatteries using iron powder as the reactant,"Journal of Alloys and Compounds. 773, 1165-1171.

[30]. Rouhani,S., Gharanjig,K., Hosseinnezhad, M., 2014. Facile synthesis of 4-nitro-N-substituted-1,8naphthalimide derivatives using ultrasound in aqueous media, Green Chemistry Letters and Reviews. 7, 174-178.

[31]. Elgemeie,GH., Mohamed,RA.. 2018. Microwave synthesis of fluorescent and luminescent dyes 
(1990-2017), Journal of Molecular Structure. 1173, 707-742.

[32]. Hosseinnezhad,M., Rouhani,S., Gharanjig,K., 2018. Extraction and application of natural pigments for fabrication of green dye-sensitized solar cells, Opto-Electronic Review. 26, 165-171.

[33]. Allouche,AR., 2011. Gabedit-A graphical user interface for computational chemistry softwares,"J Comput Chem. 32, 174-82.

[34]. Frisch,MJ., Trucks,GW., Schlegel,HB., Scuseria,GE., Robb,MA., Cheeseman,JR., 2016. Gaussian 09, revision D.01. Wallingford CT: Gaussian,"Inc .

[35]. Miyamoto,E., Yamaguchi,Y., Yokoyama, M., 1989. Ionization potential of organic pigmentfilm by atmospheric photoelectron emission analysis, Electrophotography, 28, 364-370.

[36]. Kukhta,NA., $\quad$ Volyniuk,D., $\quad$ Peciulyte,L., Ostrauskaite,J., Juska,G., Grazulevicius,JV., 2015. Structure-property relationships of star-shaped blue-emitting charge-transporting 1,3,5triphenylbenzene derivatives, Dye Pigment. 117, 122-32.

[37]. Karpicz,R., Puzinas,S., Krotkus,S., Kazlauskas,K., Jursenas,S., Grazulevicius,JV., 2011. Impact of intramolecular twisting and exciton migration on emission efficiency of multifunctional fluorenebenzothiadiazole-carbazole compounds, J Chem Phys. 134, 204508.1-9.

[38]. Santos, PL., Ward,JS., Data,P., Batsanov,AS., Bryce,MR., Dias,FB., Monkman, AP., 2016. Engineering the Singlet-triplet Energy Splitting in a TADF Molecule, J Mater Chem C, 4, 3815-3824.

[39]. Dias,FB., Santos,J., Graves,D., Data,P., Nobuyasu,RS., Fox, MA., 2016. The Role of Local Triplet Excited States in Thermally-Activated Delayed Fluorescence: Photophysics and Devices, Adv Sci. 3, 1600080.

[40]. Etherington,MK., Franchello,F., Gibson,J., Northey,T., Santos,J., Ward,JS., Data,P., Kurowska,A., Santos,PL., Graves DR., 2017. Regio- and Conformational Isomerisation Criticalto Design of Efficient Thermally-Activated Delayed Fluorescence Emitters, Nature Communications. 8, 14987.

[41]. Tanaka,H., Shizu,K., Nakanotani,H., Adachi.C., 2014. Dual Intramolecular Charge-Transfer Fluorescence Derived from a Phenothiazine-Triphenyltriazine Derivative, J Phys Chem C. 118, 15985-15994.

[42]. Okazaki,M., Takeda,Y., $\quad$ Data,P., $\quad$ Pander,P., Higginbotham,H., Monkman,AP., Minakata.S., 2017. Thermally Activated Delayed Fluorescent Phenothiazine-Dibenzo [a,j] phenazine
Phenothiazine Triads Exhibiting Tricolor-Changing Mechanochromic Luminescence, Chem Sci. 8, 26772686.

[43]. Ellinger,S., Graham,KR., Shi,P., Farley,RT., Steckler,T., Brookins,RN., Taranekar,P., 2011. Donor-Acceptor-Donor-based $\pi$-Conjugated Oligomers for Nonlinear Optics and Near-IR Emission, Chem Mater. 23, 3805-3817.

[44]. Du,X., Qi,J., Zhang,Z., Ma,D., Wang,Z., 2012. Efficient Non-doped Near Infrared Organic Light-Emitting Devices Based on Fluorophores with AggregationInduced Emission Enhancement,"J Chemistry of Materials. 24, 2178-2185.

[45]. Lippert,E., 1957. Spectroscopic determination of the dipole moment of aromatic compounds in the first excited singlet state, Z. Elektrochem., 61, 962975.

[46]. Kosower, E. M. 1982. Intramolecular donoracceptor systems. 9. Photophysics of (phenylamino)naphthalenesulfonates: a paradigm for excited-state intramolecular charge transfer. Acc. Chem. Res., 1982, 15 (8), 259-266.

[47]. Zhang,Q., Li,J., Shizu,K., Huang,S., Hirata,S., Miyazaki,H., Adachi,C. "Design of Efficient Thermally Activated Delayed Fluorescence Materials for Pure Blue Organic Light Emitting Diodes,"J. Am. Chem. Soc.134, 14706 - 14709 (2012).

[48]. Mehes,G., Nomura,H., Zhang,Q., Nakagawa,T., Adachi,C., 2012. Enhanced electroluminescence efficiency in a spiro-acridine derivative through thermally activated delayed fluorescence, Chem. Int. Ed. 51, 11311-11315.

[49]. Jayanty,S., Radhakrishnan, TP., 2004. Enhanced Fluorescence of Remote Functionalized Diaminodicyanoquinodimethanes in the Solid State and Fluorescence Switching in a Doped Polymer by Solvent Vapors, J Chem.sEur. 10, 791-797.

[50]. Xu. Shidang, Liu. Tingting, Mu. Yingxiao, Yi-Fan Wang, Chi. Zhenguo, Lo. Chang-Cheng, Liu. Siwei, Yi Zhang, Alan Lien, Xu. Jiarui, 2015. An Organic Molecule with Asymmetric Structure Exhibiting Aggregation-Induced Emission, Delayed Fluorescence, and Mechano luminescence, Angew. Chem. Int. Ed. 54, 874-878.

[51]. Tomkeviciene,A., Sutaite,J., Volyniuk,D., Kostiv,N., Simkus,G., Mimaite,V., Grazulevicius, JV., 2017. Aggregation-Induced Emission Enhancement in Charge-Transporting Derivatives of Carbazole and Tetra (tri) phenylethylene, Dyes Pigm. 140, 363374. 